\title{
KAJIAN PERBANDINGAN COBIT 5 DENGAN COBIT 2019 SEBAGAI FRAMEWORK AUDIT TATA KELOLA TEKNOLOGI INFORMASI
}

\author{
Aldy Maulana Syuhada \\ Sekolah Tinggi Manajemen Informatika dan Komputer (STMIK) LIKMI Bandung \\ Email: aldymaulanasyuhada@gmail.com
}

\begin{abstract}
Information technology or commonly called IT is the most important thing for the progress of the company, the more IT develops, good IT governance must be carried out in accordance with existing standards and must be evaluated continuously. One way to evaluate IT governance is by conducting an information technology audit. One of the frameworks that are often used to audit IT governance is COBIT. The purpose of this study is to determine the comparison between COBIT 5 and COBIT 2019 and to know the advantages and disadvantages of each of these COBITs. The method used is qualitative with literature study as a description of theory, findings and other research materials obtained as a reference to be used as a basis for research activities. The results obtained from this study are that there are several differences in terms of the general picture, that COBIT 2019 has a factor design, in terms of domains, in COBIT 2019 there are three additional and objective domains. Furthermore, in terms of principles, COBIT 2019 has 9 principles that have been developed from the previous COBIT. Furthermore, from the goal cascade and from performance calculations, COBIT 5 only uses the capability level but in 2019 COBIT there is an addition to the capability level and maturity level. In terms of advantages COBIT 5 is more widely used, whereas from the drawbacks it is not flexible, while COBIT 2019 has the advantages of being more flexible and lacks in principles and details of domination so it will be more difficult to implement.
\end{abstract}

Keywords: cobit framework; it governance; cobit 5; cobit 2019

\section{Abstrak}

Teknologi Informasi atau biasa disebut TI merupakan hal terpenting bagi kemajuan perusahaan, semakin berkembangkan TI maka harus dilakukan tata kelola TI yang baik sesuai dengan standart yang ada dan harus dievaluasi terus menerus. Salah satu cara untuk mengevaluasi tata kelola TI yaitu dengan dilakukanya audit teknologi informasi. Salah satu framework yang sering digunakan untuk melakukan audit tata kelola TI adalah COBIT. Tujuan dari penelitian ini adalah mengetahui perbandingan antara COBIT 5 dengan COBIT 2019 serta mengetahui kekurangan dan kelebihan dari masing-masing COBIT tersebut. Metode yang digunakan yaitu kualitatif dengan studi literatur yang berisi tentang uraian teori, temuan dan bahan penelitian lain yang diperoleh sebagai acuan untuk dijadikan landasan kegiatan penelitian. Hasil yang diperoleh dari penelitian ini yaitu terdapat beberapa perbedaan dari segi gambaran secara umum pada COBIT 2019 memiliki desain faktor, segi domain, pada COBIT 2019 terdapat tiga domain tambahan dan bersifat objective. Selanjutnya dari segi 
prinsip COBIT 2019 memiliki 9 prinsip yang telah dikembangkan dari COBIT sebelumnya. Selanjutnya dari goal cascade dan dari perhitungan kinerja, COBIT 5 hanya menggunakan capability level tetapi pada COBIT 2019 adanya penambahan menjadi capability level dan maturity level. Dari segi kelebihan COBIT 5 lebih banyak digunakan sedangkan dari kekurangannya tidak bersifat flexible sedangkan COBIT 2019 kelebihannya lebih bersifat flexible dan kekurannya prinsip dan detail domainya lebih banyak sehingga akan lebih sulit dalam implementasi.

Kata Kunci: framework cobit; tata kelola ti; cobit 5; cobit 2019

Coresponden Author

Email: aldymaulanasyuhada@gmail.com Artikel dengan akses terbuka dibawah lisensi

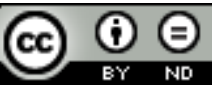

\section{Pendahuluan}

Teknologi Informasi (TI) saat ini merupakan sesuatu hal yang sangat penting bagi suatu organisasi, karena dengan adanya TI dapat membantu dalam peningkatan efektifitas dan efisiensi proses bisnis perusahaan. Penerapan TI sendiri memiliki resiko yang tinggi dan investasi yang besar, penerapan TI perlu pengawasan secara menyeluruh terhadap mekanisme tata kelola TI agar tujuan bisnis suatu organisasi benar-benar dapat dicapai secara efektif dan efisien dengan adanya penggunaan TI (Widilianie \& Manuputty, 2019). Teknologi yang telah ada haruslah dikontrol atau dilakukan pengecekan terhadap tata kelola TI yang baik. 3 manfaat utama yang akan didapat ketika perusahaan telah menerapkan tata kelola TI yang baik yaitu benefit realization (realisasi Manfaat), Risk Optimization (Optimalisasi Risiko) dan Resource Optimalization (Optimalisasi sumber daya) (Aditya, Mulyana, \& Mulyawan, 2019).

Tata kelola TI adalah struktur kebijakan atau prosedur dan kumpulan proses organisasi yang bertujuan untuk memastikan kesesuaian penerapan TI dengan dukungannya terhadap pencapaian tujuan institusi, dengan cara mengoptimalkan keuntungan dan kesempatan yang ditawarkan TI, mengendalikan penggunaan terhadap sumber daya TI dan mengelola risiko-risiko terkait TI (Hilmawan, H., Nurhayati, O. D., \& Windasari, 2015). Tata kelola teknologi informasi adalah sebuah proses dimana organisasi menyelaraskan IT actions dengan visi dan misi yang ingin dicapai organisasi. Hal ini dicapai dengan mengambil keputusan tepat (siapa memutuskan apa) dan menerapkan sebuah framework yang akuntabilitas (siapa bertanggung jawab tentang apa) sehingga setiap keputusan yang diambil dapat mengembangkan penggunaan TI di dalam organisasi (Maskur, Adolong, \& Mokodongan, 2018). Tata kelola TI merupakan tanggung jawab dari pimpinan dan manajemen institusi. Pimpinan dan manajemen institusi tidak harus menjadi ahli di bidang TI, tetapi mereka perlu menyadari peranan dan tanggung jawabnya terhadap arah penerapan TI organisasi untuk menjaga keselarasan dengan tujuan organisasi (Maskur et al., 2018). 
Salah satunya dengan melakukan audit. Audit pada dasarnya adalah proses sistematis dan obyektif dalam memperoleh dan mengevaluasi bukti-bukti tindakan ekonomi, guna memberikan asersi/pernyataan dan menilai seberapa jauh tindakan ekonomi sudah sesuai dengan kriteria yang berlaku dan mengkomunikasikan hasilnya kepada pihak terkait (Suryono, Darwis, \& Gunawan, 2018). Audit tata kelola berguna agar dapat mengevaluasi suatu organisasi sejauh mana tingkat kematangan tata kelola TI dan dapat memperbaiki penyimpangan yang ada dalam implementasi tata kelola TI (Imami, L. W., Suprapto, \& Mursityo, 2018). Salah satu framework audit yang dapat digunakan yaitu Control Objective for Information \& Related Technology (COBIT).

COBIT adalah salah satu framework yang digunakan untuk standar audit, COBIT merupakan standar yang dinilai lengkap dan cakupan yang menyeluruh sebagai framework audit. COBIT dikembangkan secara berkala oleh ISACA. Didalam COBIT ini terdapat beberapa Domain yang digunakan untuk proses audit (Candra, Atastina, \& Firdaus, 2015).

COBIT (Control Objectives for Informtion and Related Technology) merupakan sekumpulan dokumentasi dan panduan yang mengarahkan pada tata kelola TI dan manajemen TI yang dapat membantu auditor, manajemen, dan pengguna (user) untuk menjembatani pemisah antara resiko bisnis, kebutuhan kontrol, dan permasalahanpermasalahan teknis. COBIT dikembangkan oleh sebuah lembaga Tata Kelola TI institute (ITGI) yang merupakan bagian dari System Information and Control Association (ISACA) (Hidayat, 2015).

Prinsip dasar pada framework COBIT adalah menyediakan informasi yang diperlukan untuk mencapai tujuan perusahaan atau organisasi. Perusahaan atau organisasi perlu mengatur dan mengatur sumber daya teknologi informasi dengan menggunakan sekumpulan proses teknologi informasi yang terstruktur sehingga dapat memberikan informasi yang dibutuhkan (Ekowansyah, Chrisnanto, \& Sabrina, 2017).

Dengan berkembangnya Tata kelola TI berkembang pula Domain COBIT. COBIT 5 merupakan sebuah kerangka menyeluruh yang dapat membantu perusahaan dalam mencapai tujuannya untuk tata kelola dan manajemen teknologi informasi perusahaan (ISACA., 2012; ISACA, 2012, 2013). COBIT mendefinisikan komponen untuk membangun dan menopang sistem tata kelola: proses, struktur organisasi, kebijakan dan prosedur, arus informasi, budaya dan perilaku, keterampilan, dan infrastruktur, mendefinisikan faktor desain yang harus dipertimbangkan oleh perusahaan untuk membangun sistem tata kelola yang paling sesuai dan menangani masalah tata kelola dengan mengelompokkan komponen tata kelola yang relevan ke dalam tata kelola dan manajemen (ISACA, n.d.).

Salah satu contoh perkembangan yang dilakukan COBIT yaitu COBIT 5 dan COBIT 2019. Versi terbaru dari COBIT adalah COBIT 2019. Versi terbaru ini dikeluarkan pada tahun 2018. COBIT 2019 merupakan pembaruan besar besaran yang ada pada versi COBIT sebelumnya. Dimana versi COBIT 2019 merupakan versi penyesuaian perkembangan dengan teknologi terbaru saat ini. Selain itu penyesuain juga dengan framework lain seperti ITIL, TOGAF dan CMII (Aliyhafiz, 2020). 
Pada standar COBIT yang telah dibuat, pastinya ada kekurangan dan kelebihannya dari masing-masing framework.

Berdasarkan uraian diatas, maka peneliti bermaksud untuk mengungkapkan perkembangan yang dilakukan dan kelebihan serta kekurangan dari masing-masing COBIT antara COBIT 5 dan COBIT 2019.

\section{Metode Penelitian}

Metode penelitian ini menggunakan kualitatif yaitu dengan studi literatur yang berisi tentang uraian teori, temuan dan bahan penelitian lain yang diperoleh sebagai acuan untuk dijadikan landasan kegiatan penelitian. Referensi yang diambil yaitu dari COBIT 5: Enabling Processes, COBIT: 5 A Business Framework for the Governance and Management of Enterprise IT, COBIT 5 : Process Assessment Model (PAM) dan COBIT 2019 Framework: Introduction and Methodology.

\section{Hasil dan Pembahasan}

\section{A. Perbandingan COBIT 5 dan COBIT 2019}

Berdasarkan hasil studi literatur yang telah dilakukan, terdapat beberapa perbedaan antara framework COBIT 5 dan COBIT 2019. Berikut perbedaan antara kedua framework COBIT:

\section{Tabel 1}

\section{Perbandingan COBIT 5 dan COBIT 2019}

\begin{tabular}{|c|c|c|c|}
\hline No & Point-point & COBIT 5 & COBIT 2019 \\
\hline 1 & Gambaran COBIT & $\begin{array}{l}\text { Tidak memiliki desain } \\
\text { faktor }\end{array}$ & Memiliki desain faktor \\
\hline 2 & Prinsip & Memiliki 5 prinsip & Memiliki 9 prinsip \\
\hline \multirow{3}{*}{3} & \multirow{3}{*}{$\begin{array}{l}\text { Detail Domain } \\
\text { Proses }\end{array}$} & $\begin{array}{l}\text { Disebut proses tata } \\
\text { kelola TI }\end{array}$ & $\begin{array}{l}\text { Disebut objective tata } \\
\text { kelola TI }\end{array}$ \\
\hline & & $\begin{array}{l}\text { Pada tiap domain } \\
\text { menjadi kata kerja, } \\
\text { Contoh : manage }\end{array}$ & $\begin{array}{l}\text { Pada tiap domain } \\
\text { menjadi kata yang } \\
\text { lebih objectif, contoh: } \\
\text { Managed }\end{array}$ \\
\hline & & Terdapat 37 domain & $\begin{array}{l}\text { Terdapat } 40 \text { domain (3 } \\
\text { domain tambahan) }\end{array}$ \\
\hline 4 & Goal Cascade & $\begin{array}{l}\text { Terdapat } 5 \text { goal } \\
\text { cascade }\end{array}$ & $\begin{array}{l}\text { Terdapat } 4 \text { goal } \\
\text { cascade dan tujuan } \\
\text { perusahaan dengan } \\
\text { tujuan TI diselaraskan } \\
\text { terlebih dahulu }\end{array}$ \\
\hline 5 & $\begin{array}{l}\text { Perhitungan tingkat } \\
\text { kematangan }\end{array}$ & Capability Level & $\begin{array}{l}\text { Maturity Level dan } \\
\text { capability level }\end{array}$ \\
\hline 6 & Tata kelola & Enabler & $\begin{array}{l}\text { Komponen Sistem } \\
\text { Tata Kelola }\end{array}$ \\
\hline
\end{tabular}

\section{B. Gambaran COBIT}


Dari gambaran COBIT 2019 ini mengalami beberapa perubahan, salah satunya yaitu terdapat desain faktor, dengan adanya desain faktor terlebih dahulu diharapkan implementasi COBIT 2019 sesuai dengan kondisi perusahaan yang akan mengimplementasikan. Sesuai dengan penjelasan pada bab 2 mengenai desain faktor, perusahaan dapat mendesain terlebih dahulu letak perusahaan itu dimana sehingga nanti didapatkan hasil yang dapat mempermudah proses audit dan penentuan kinerja perusahaan dengan COBIT 2019.

\section{Prinsip COBIT}

Dari segi prinsipnya jelas berbeda antara COBIT 5 dan COBIT 2019, hal ini dapat dilihat dari jumlah yang dimiliki oleh masih-masing COBIT. Untuk COBIT 5 pembagiannya ada 5 prinsip yaitu:

1. Menemukan kebutuhan stakeholder.

2. Mencakup ujung ke ujung enterprise.

3. Mengaplikasikan yang tunggal, mengintegrasikan framework.

4. Mengaktifkan pendekatan holistik.

5. Memisahkan tata kelola dengan manajemen.

Sedangkan pada COBIT 2019 prinsipnya dibagi kedalam dua bagian, yaitu:

1. Prinsip berdasarkan sistem tata kelola

a. Memenuhi kebutuhan para pemangku kepentingan (stakeholder)

b. Memungkinkan pendekatan yang holistik

c. Penerapan sistem tata kelola yang dinamis

d. Memisahkan tata kelola dengan manajemen

e. Dapat disesuaikan dengan kebutuhan organisasi

f. Mencakup organisasi secara menyeluruh

2. Prinsip berdasarkan kerangka tata kelola

a. Hubungan antar komponen, untuk memaksimalkan konsistensi dan memungkinkan otomatisasi.

b. Untuk mengatasi masalah baru dengan cara yang paling fleksibel, dengan tetap menjaga integritas dan konsistensi. Kerangka tata kelola harus terbuka dan fleksibel. Ini harus memungkinkan penambahan konten baru dan kemampuan.

c. Kerangka tata kelola harus selaras dengan standar, kerangka kerja, dan peraturan utama yang relevan.

Dari prinsip-prinsip berikut, dapat disimpulkan bahwa COBIT 2019 itu mengadopsi dari COBIT 5, hal ini dapat dilihat dari prinsip antara tata kelola dan manajemen itu dipisahkan dan tetap harus memenuhi kebutuhan para pemangku kepentingan (stackholder), namun pada perkembangan COBIT 2019 ingin bersifat terbuka dan flexible, juga memungkinkan penambahan konten baru artinya tidak memaksa perusahaan untuk mengikuti prinsip-prinsip yang ada. Sehingga dengan flexiblenya sistem tata kelola pada COBIT 2019 tidak akan kaku dan akan terus mengikuti jamannya. Hal lain yang dapat dikatakan flexible pada COBIT 2019 yaitu dengan ditunjukannya objective bukan proses, yang dimaksud objective disini adalah mencapai hasil, karena pada COBIT 2019 juga pada domainnya menunjukan hasil. 


\section{Detail Domain Proses COBIT}

Pada masing-masing COBIT akan berbeda jenis penamaan domainnya, perbedaan nama domain COBIT 5 dinamakan proses tata kelola TI sedangkan pada domain COBIT 2019 disebut objective Tata Kelola, dari penamaan tersebut, berpengaruh terhadap detail domain yang ada yaitu sebagai contoh pada COBIT 5 terdapat domain proses "Manage inovation" atau kelola inovasi, pada COBIT 5 berikut artinya lebih menekankan kepada proses dari pengelolaan inovasi bukan terhadap hasil yang dicapai. Tetapi pada COBIT 2019 yang asalnya "Manage Inovation" menjadi "Managed Inovation" atau Inovasi yang dikelola artinya COBIT 2019 lebih menekankan kepada hasil dan diharapkan, proses tersebut dapat dilakukan dengan baik sesuai dengan prosedur yang ada.

Dari segi point-point domain juga, COBIT 2019 ini ada beberapa penambahan dan pemecahan yaitu:

\section{APO14 - Managed Data}

Yang diharapkan dengan adanya objective domain ini, pada COBIT 2019 dapat mengelola data yang ada pada perusahaan sehingga dapat menghasilkan suatu informasi.

2. BAI01 - Managed Programs (Pada COBIT 5 Digabung dengan Manage Program \& Project)

Yang diharapkan dengan adanya objective domain ini pada COBIT 2019 hasil dari program yang telah dijalankan dapat dkelola dengan baik

3. BAI11 - Managed Project (Pada COBIT 5 Digabung dengan Manage Program \& Project)

Yang diharapkan dengan adanya objective domain ini pada COBIT 2019 hasil dari project yang telah dijalankan dapat dkelola dengan baik dan hasilnya pun akan terpisah antara program dan project

4. MEA01 - Managed Assurance

Yang diharapkan dengan adanya objective domain ini pada COBIT 2019 hasil dari jaminan yang telah implementasikan dapat dikelola dengan baik

Dengan telah ditambahkan objective dari domain diharapkan pula COBIT 2019 lebih sesuai dengan kondisi perusahaan dan dapat diimplementasikan dengan baik.

Pada COBIT 2019 ini juga telah ditambahkan dua proses pada 2 domain yang berbeda yaitu Managed Data di APO dan Managed Assurance di MEA, dan pada COBIT 2019 juga ada proses yang dipisah yaitu Managed Program dan Managed Project yang asalnya pada COBIT 5 disatukan. Hal ini memungkinkan COBIT 2019 dapat menentukan data dan Jaminan apa yang dapat dikelola. Sedangkan untuk Managed Program dan Project dipisahkan agar lebih detail terhadap hasil yang didapat baik dalam program maupun dalam project sehingga hasil yang didapatkan akan lebih detail dan terperinci.

\section{E. Goal Cascade COBIT}

Berikut dari segi goal cascade antara COBIT 5 dan COBIT 2019 : 
1. Pada COBIT 5 tujuan atau goal cascade diawali dengan kebutuhan stackholder atau pemilik perusahaan selanjutnya diturunkan ke tujuan dari perusahaan setelah itu diturunkan ke tujuan dari TI-nya seperti apa dan selanjutnya adanya tujuan dari enabler.

2. Pada COBIT 2019 goal cascade sebenarnya hampir sama seperti pada COBIT 5 yaitu menentukan kebutuhan dari stackholder atau pemilik perusahaan selanjutnya diturunkan menjadi tujuan dari perusahaan, setelah tujuan dari perusahaan terpenuhi, selanjutnya diturunkan menjadi keselarasan antara tujuan perusahaan dan tujuan TI. Jadi pada COBIT 2019 ini tujuan TI dan tujuan perusahaan harus selaras terlebih dahulu, setelah selaras baru dapat diturunkan kembali ke objective tata kelola dan manajemen.

Dari uraian diatas dapat disimpulkan bahwa perbedaannya terletak pada tujuan TI yang pada COBIT 5 menjadi tujuan TI tersendiri sedangkan pada COBIT 2019 tujuan TI dan tujuan perusahaan itu diselaraskan terlebih dahulu agar lebih sesuai dengan tujuan perusanaan.

\section{F. Pengukuran kinerja COBIT}

Untuk pengukuran tingkat kinerja COBIT, pada COBIT 5 dan COBIT 2019 memiliki perbedaan. Jika pada COBIT 5 hanya menggunkan model capability level dalam pengukuran tingkat kinerjanya, hal ini mengacu pada ISO 15504/ISO 33000, pada capability model COBIT 5 ini terdapat 6 level dari level 0 hingga level 5. Sedangkan pada COBIT 2019 telah disesuaikan dengan Capability Maturity Model Integration (CMMI) sehingga pada COBIT 2019 selain menggunakan capability level yang berhubungan dengan process area ditambahkan juga maturity level yang merujuk pada satu set atau kumpulan pada process area. Untuk tingkatan level-nya antara maturity dan capability pada COBIT 2019 itu sama yaitu 0 sampai dengan 5 yang menunjukan bahwa semakin tinggi level, maka semakin bagus tingkat kematangan dari suatu perusahaan.

\section{Kesimpulan}

Berdasarkan hasil pembahasan yang telah disampaikan sesuai dengan studi literatur yang telah dilakukan, maka dapat diambil kesimpulan bahwa Perbandingan antara COBIT 5 dan COBIT 2019 dapat dilihat dari gambaran umum pada COBIT 5 belum ada faktor desain, sedangkan pada COBIT 2019 telah ditambahkan faktor desain sehingga dapat lebih menyesuaikan dengan perusahaan, prinsip pada COBIT 5 lebih ringkas sehingga dapat memudahkan juga dalam implementasi sedangkan pada COBIT 2019 lebih banyak dan memungkinkan untuk flexible, domain pada COBIT 5 lebih bersifat proses sedangkan pada COBIT 2019 lebih objective dan detail domain pada COBIT 2019 yang memiliki beberapa tambahan dan menekankan pada hasil yang dicapai, Tujuan dari COBIT 5 yaitu setelah tujuan dari perusahaan, harus ditentukan juga tujuan dari TI-nya sedangkan pada COBIT 2019 tujuan TI agar selaras dahulu dengan tujuan perusahaan, perhitungan tingkat kinerja pada COBIT 5 yaitu dengan capability level karena menyesuaikan dengan ISO 15504/ISO 33000 sedangkan pada COBIT 2019 telah 
disesuaikan dengan CMMI dengan menambahkan maturity level dan capability level, Secara tujuan tata kelola, pada COBIT 5 terdapat 7 enabler sedangkan pada COBIT 2019 dinamakan 7 komponen tata kelola.

Sedangkan untuk kekurangan dari masing COBIT 5 yaitu tidak bersifat flexible sehingga tidak dapat menyesuaikan dengan kemajuan zaman, domain masih menyatakan proses tidak menekankan pada hasil dan tidak adanya desain faktor terlebih dahulu sehingga tidak ada acuan untuk keselarasan dengan perusahaan. Untuk kelebihan dari COBIT 5 yaitu COBIT 5 sudah banyak diimplementasikan di perusahaan maupun di instansi pendidikan dan domain proses lebih ringkas sehingga dapat memudahkan untuk diimplementasikan.

Sedangkan untuk kekurangan dari masing COBIT 2019 yaitu Domain proses lebih banyak sehingga dapat mempersulit dalam proses audit dan dari segi prinsip COBIT 2019 lebih banyak sehingga dapat mempersulit proses implementasi. Untuk kelebihan dari COBIT 2019 yaitu dari segi prinsip COBIT 2019 ini lebih bersifat flexible sehingga dapat menyesuaikan dengan perubahan zaman, domain lebih menekankan pada hasil yang dicapai sehingga akan lebih terarah, proses pada domain lebih lengkap karena ada penambahan beberapa proses pada suatu domain, tujuan COBIT 2019 lebih baik, karena menyesuaikan dengan tujuan perusahaan dan adanya desain faktor, sehingga dapat memudahkan dalam penyesuaian dengan perusahaan. 


\section{BIBLIOGRAFI}

Aditya, Mohamad Adhisyanda, Mulyana, R. Dicky, \& Mulyawan, Ali. (2019). Perbandingan Cobit 2019 Dan Itil V4 Sebagai Panduan Tata Kelola Dan Management IT. Jurnal Computech \& Bisnis, 13(2), 100-105.

Aliyhafiz. (2020). Pengertian, Prinsip, dan Enabler COBIT Terbaru. retrieved by: aliyhafiz.com

Candra, Rio Kurnia, Atastina, Imelda, \& Firdaus, Yanuar. (2015). Audit Teknologi Informasi Menggunakan Framework COBIT 5 Pada Domain DSS (Deliver, Service, And Support) (Studi kasus: IGRACIAS Telkom University). E-Proceedings of Engineering, 2(1).

Ekowansyah, Erdis, Chrisnanto, Yulison H., \& Sabrina, Puspita Nurul. (2017). Audit Sistem Informasi Akademik Menggunakan COBIT 5 di Universitas Jenderal Achmad Yani. Seminar Nasional Komputer dan Informatika (Senaski), 201-206.

Hidayat, A. E. (2015). Audit Control Capability Level Tata Kelola Sistem Informasi Menggunakan COBIT 5. Jurnal Informasi, Bandung.

Hilmawan, H., Nurhayati, O. D., \& Windasari, I. P. (2015). Analisis Tata Kelola Teknologi Informasi Menggunakan Kerangka Kerja COBIT 5 pada AMIN JTC Semarang. Jurnal Teknologi Dan Sistem Komputer, Vol.3, No., 247-252.

Imami, L. W., Suprapto, \& Mursityo, Y. T. (2018). Audit Tata Kelola Teknologi Informasi pada Dinas Komunikasi dan Informatika (DISKOMINFO) Kota Probolinggo Menggunakan Kerangka Kerja COBIT 4.1 Domain Plan and Organise dan Acquire and Implement. Jurnal Pengembangan Teknologi Informasi Dan Ilmu Komputer, 3.

ISACA. (2012). COBIT 5: A business framework for the governance and management of enterprise IT. USA: Isaca.

ISACA. (2018). COBIT 2019 Framework: Introduction and Methodology. In 2018. USA: ISACA.

ISACA, COBIT. (2012). 5: Enabling Processes Governance and Management Practices. United States of America: ISACA \& ITGI.

ISACA, COBIT. (2013). 5: Process Assessment Model (PAM)-Using COBIT 5. Illinois: 
Kajian Perbandingan Cobit 5 dengan Cobit 2019 Sebagai Framework Audit Tata Kelola Teknologi Informasi

Isaca.

Maskur, Maskur, Adolong, Nixon, \& Mokodongan, Rusliy. (2018). Implementasi Tata Kelola Teknologi Informasi Menggunakan Framework Cobit 5 di BPMPTSP Bone Bolango. Masyarakat Telematika Dan Informasi: Jurnal Penelitian Teknologi Informasi Dan Komunikasi, 8(2), 109-126.

Suryono, Ryan Randy, Darwis, Dedi, \& Gunawan, Surya Indra. (2018). Audit Tata Kelola Teknologi Informasi Menggunakan Framework Cobit 5 (Studi Kasus: Balai Besar Perikanan Budidaya Laut Lampung). Jurnal Teknoinfo, 12(1), 16-22.

Widilianie, Eka, \& Manuputty, Augie David. (2019). Evaluasi Kinerja SI Project Management Menggunakan Framework Cobit 5 Subdomain MEA 01. Jurnal SITECH: Sistem Informasi dan Teknologi, 2(1), 39-50. 